\title{
Does One Health require a novel ethical framework?
}

\author{
Jane Johnson, ${ }^{\oplus 1,2}$ Chris Degeling ${ }^{3}$
}

${ }^{1}$ Westmead Clinical School, Sydney Medical School, The University of Sydney, Camperdown, New South Wales, Australia 2Department of Philosophy, Macquarie University, NSW, Australia

${ }^{3}$ Australian Centre for Health Engagement, Evidence and Values, University of Wollongong, Wollongong, New South Wales, Australia

\section{Correspondence to} Dr Jane Johnson, Westmead Clinical School, Sydney Medical School, The University of Sydney, Camperdown, NSW 2050, Australia;

jane.johnson@sydney.edu.au

Received 2 July 2018 Revised 7 January 2019 Accepted 23 January 2019 Published Online First 16 February 2019

\begin{abstract}
Emerging infectious diseases (EIDs) remain a significant and dynamic threat to the health of individuals and the well-being of communities across the globe. Over the last decade, in response to these threats, increasing scientific consensus has mobilised in support of a One Health $(\mathrm{OH})$ approach so that $\mathrm{OH}$ is now widely regarded as the most effective way of addressing EID outbreaks and risks. Given the scientific focus on $\mathrm{OH}$, there is growing interest in the philosophical and ethical dimensions of this approach, and a nascent $\mathrm{OH}$ literature is developing in the humanities. One of the key issues raised in this literature concerns ethical frameworks and whether $\mathrm{OH}$ merits the development of its very own ethical framework. In this paper, we argue that although the $\mathrm{OH}$ approach does not demand a new ethical framework (and that advocates of $\mathrm{OH}$ can coherently adhere to this approach while deploying existing ethical frameworks), an $\mathrm{OH}$ approach does furnish the theoretical resources to support a novel ethical framework, and there are benefits to developing one that may be lost in its absence. We begin by briefly explaining what an $\mathrm{OH}$ approach to the threats posed by EIDs entails before outlining two different ways of construing ethical frameworks. We then show that although on one account of ethical frameworks there is no need for $\mathrm{OH}$ to generate its own, there may be advantages for its advocates in doing so.
\end{abstract}

\section{INTRODUCTION}

Emerging infectious diseases (EIDs) remain a significant and dynamic threat to the health of individuals and the well-being of communities. Globally, it is estimated that at least 15 million deaths a year are a direct result of EIDs and zoonoses. ${ }^{1}$ Over the last decade in response to these threats, increasing scientific consensus has mobilised in support of a One Health $(\mathrm{OH})$ approach such that $\mathrm{OH}$ is now widely regarded as the most effective way of addressing EID outbreaks and risks. ${ }^{2} 3$ Thus, $\mathrm{OH}$ approaches are beginning to be used to guide health policy and public health activities.

Given the scientific focus on $\mathrm{OH}$, there is growing interest in the philosophical and ethical dimensions of this approach, and a nascent $\mathrm{OH}$ literature is developing in the humanities. Reviewing this literature has revealed that a key issue concerns ethical frameworks and whether $\mathrm{OH}$ merits the development of its own framework. ${ }^{4}$ This is an issue because resources are limited for the management of EIDs, and prioritisation and resource allocation require ethical decisions about what is valued, what must be protected and what is dispensable. If policy makers and practitioners are to use $\mathrm{OH}$ to guide policy and action, the question arises, do they require new principles and frameworks to do so?
In this paper, we argue that although the $\mathrm{OH}$ approach does not demand a new ethical framework (and that advocates of $\mathrm{OH}$ can coherently adhere to this approach while deploying existing ethical frameworks), an $\mathrm{OH}$ approach does furnish the theoretical resources to support its own framework, and there are benefits to developing one that may be lost in its absence.

We begin by briefly explaining what an $\mathrm{OH}$ approach to the threats posed by EIDs entails before outlining two different ways of construing ethical frameworks: one in which they are regarded as value-neutral tools, and another according to which they embed particular values. We then show that although on this first account there is no need for $\mathrm{OH}$ to generate its own framework, there may be advantages for its advocates in doing so.

\section{WHAT IS ONE HEALTH?}

$\mathrm{OH}$ is generally construed as an integrated approach to understanding and managing disease. Although primarily associated with the prevention and control of EIDs, the approach is also relevant to dealing with endemic and zoonotic animal diseases, as well as securing food safety. ${ }^{56}$ In its most comprehensive form, it extends to fostering the health of humans, animals and their shared environments. ${ }^{78}$ The bulk of discussion in our paper will concern the more conventional disease focused understanding of $\mathrm{OH}$, though we will also touch on this broader definition.

The $\mathrm{OH}$ approach to disease is grounded in a well-established scientific fact: that the health of humans, animals and the environment are interdependent. These domains overlap so that what happens in one can have implications for the others. Non-human animals are a reservoir for pathogens that impact on humans (and vice versa), and the ways in which human and animals interact, as well as the nature of the environments in which they do so, generate opportunities for disease development and exchange. ${ }^{9}$ Integral to an $\mathrm{OH}$ approach is the acknowledgement that disease transmission is not simply about pathogens, biological mechanisms and proximate causes but rather involves fundamental distal or 'upstream' structural drivers too. For example, social, economic, political and ecological factors can all play a crucial role in the emergence and spread of infectious disease.

In the face of these facts about disease, in its strongest form $\mathrm{OH}$ responds by advocating a deconstruction of the disciplinary silos ${ }^{10}$ that have isolated the medical and social sciences that deal with human disease, animal disease and ecological concerns. ${ }^{11} 12$ Interdisciplinary research is construed as central, as is interventionist practice across a broad spectrum of fields. ${ }^{113} 14$ 


\section{ETHICAL FRAMEWORKS AND OH}

Since it is a relatively new approach, $\mathrm{OH}$ has received little philosophical attention. However the philosophical work that has been done on $\mathrm{OH}$ has included a recognition that this inattention ought to be rectified, in order to make the most of the kind of intersectoral collaboration that $\mathrm{OH}$ facilitates. ${ }^{4}{ }^{14} \mathrm{We}$ agree with Verweij and Bovenkerk on this point; philosophy has much to offer the developing field of $\mathrm{OH}$. For instance, there is a need for conceptual clarity to avoid some of the pitfalls generated by interdisciplinary research and practice, including from individuals in different disciplines talking at cross-purposes and operating according to different norms that undermine the approach's effectiveness. ${ }^{15}$ Beyond addressing problems that arise from the interdisciplinary nature of $\mathrm{OH}$, philosophy has more to contribute. As there is no agreed on $\mathrm{OH}$ ethics (though Capps and Lederman ${ }^{16}$ have sketched out key features they argue should form part of any $\mathrm{OH}$ ethics), there is work for philosophers to do in clarifying the conceptual terrain and making explicit the assumptions which underpin $\mathrm{OH}$, as well as developing principles and strategies to help resolve the inevitable conflicts that will arise in the implementation of a $\mathrm{OH}$ approach. $\mathrm{OH}$ commands philosophical consideration on these and other matters, not least because of the importance of the problems it deals with (eg, the complexity of issues surrounding disease management at the human-animal-environment interface, the burden of global disease and so on) and the growing significance to-and traction it has within-allied disciplines such as global and public health. ${ }^{17}$

One of the philosophical questions that can be posed in the context of discussions of $\mathrm{OH}$ is whether it demands a new ethical framework. ${ }^{4}$ This question is important because of what frameworks can do and what they represent. Though the concept of an ethical framework is used in a confusing variety of ways in public health, we follow Dawson ${ }^{18}$ in thinking their primary purpose is deliberative; ethical frameworks can help scaffold and guide decision making regarding public health policy and action. This should make such frameworks a particularly soughtafter resource in applied contexts with practitioners who may lack philosophical skills and find engaging in ethical reasoning challenging. They may be especially valued when there are time pressures associated with decision making, as can be the case with EIDs. Verweij and Bovenkerk ${ }^{4}$ ultimately conclude that any temptation to develop a new ethical framework for $\mathrm{OH}$ ought to be resisted, as it is simply not required. However, even if this is the case, it will be helpful for practitioners attempting to apply $\mathrm{OH}$ to understand how $\mathrm{OH}$ sits within or relates to existing frameworks.

In what follows we will examine two conceptions of ethical frameworks and how they bear on the question of the value and need (or otherwise) for a new ethical framework for $\mathrm{OH}$.

\section{Frameworks as value-neutral tools}

On the first view of frameworks we will consider, they should be agnostic regarding values; ethical frameworks are simply to be regarded as value-free tools which form part of a procedural approach to decision making. Frameworks involve no prior commitment to particular values that are embedded in or shape their structure and functioning. This separation can liberate frameworks from being caught up in contentious and potentially distracting debates. As Dawson states 'the use of a framework allows a certain detachment from potentially controversial theoretical issues (allowing a pragmatic postponement of discussions about justificatory issues)' (p. 200). ${ }^{18}$
Table 1 Grill and Dawson's pluralist ethical framework

\begin{tabular}{lll}
\hline 1. & Identification: & Identify relevant alternatives. \\
2. & Distinguishing: & $\begin{array}{l}\text { Distinguish relevant empirical differences between } \\
\text { alternatives, including contingencies. }\end{array}$ \\
3. & Ranking: & Rank, as far as possible, alternatives from best to worst. \\
4. & Evaluation: & $\begin{array}{l}\text { Make explicit, as far as possible, in what sense some } \\
\text { alternatives are better than others. }\end{array}$ \\
5. Documentation: & $\begin{array}{l}\text { Submit the result of the evaluation to a designated } \\
\text { oversight institution. }\end{array}$
\end{tabular}

From Grill and Dawson, ${ }^{19}$ pp. $293-294$.

When frameworks are considered as involving no prior commitment to particular values, then there is no reason for a specially $\mathrm{OH}$ framework; in these circumstances, $\mathrm{OH}$ makes no demand for a new ethical framework. What it does, however, is contribute a set of considerations that, although potentially fruitful, may otherwise be absent from the discussion. To illustrate what we mean in greater depth, consider the pluralist ethical framework proposed by Grill and Dawson. ${ }^{19}$ This framework sets out steps that should be followed to determine the best course for public health policy and action. (These steps are shown in table 1.) Alert to the $\mathrm{OH}$ perspective, alternate approaches (which might otherwise be missed) can be identified at step 1 and worked through using this existing framework. If we follow this approach, we are led to ask what kind of considerations and alternate approaches might be generated by focusing on $\mathrm{OH}$ ?

One of the strengths of $\mathrm{OH}$ is that the approach draws attention to an environmental dimension that may be relevant in ethical decision making but which, despite initial prominence in domains like bioethics, appears to have slipped off the disciplinary agenda. ${ }^{20}$ For instance, $\mathrm{OH}$ might make visible an environmental strategy to address a phenomenon like Hendra virus. In Australia, at least two species of flying fox are hosts for Hendra virus. Although infection of humans and horses is rare, its consequences are catastrophic. ${ }^{21}$ The destruction of flying fox habitat means humans, horses and flying foxes are more likely to come into contact, creating possibilities for disease transmission. ${ }^{22} \mathrm{On}$ an $\mathrm{OH}$ outlook, a plausible strategy to address the likelihood of outbreaks would be to change policies around land clearing so that bat habitat is preserved. ${ }^{23} 24$ This strategy could be considered alongside more traditional public health measures such as vaccination of horses. Valuing the environment and promoting environmental and animal health in the manner suggested by $\mathrm{OH}$ could be contrasted with a strategy to Hendra virus, which prioritised only human life and health. For example, since flying foxes are crucial to disease transmission, relocating or culling could represent an alternative. Though such a strategy would (with current methods at least) create further stress in animal populations exacerbating the problem (stressed flying foxes shed disease) or simply move it to other areas, it is theoretically possible to develop methods that could eradicate flying foxes without increasing Hendra disease risk for humans (eg, through sterilisation), if the broader environment was not deemed important.

Acknowledging and valuing the interdependence of human and non-human health is another feature of $\mathrm{OH}$ that may be imported into existing ethical frameworks for consideration. For instance, in the context of Ebola virus and vaccine development, Capps and Lederman ${ }^{16}$ (explicitly appealing to $\mathrm{OH}$ ) have proposed developing shared immunity between humans and other primates given both groups can be impacted by Ebola. They suggest that inoculating wild primates with vaccines that 
have been tested and found to be safe and efficacious in primates could serve to protect those animals that are vaccinated and the humans who come into contact with them, particularly while vaccines for humans are still being tested.

In addition to highlighting environmental concerns and the interdependence of human and non-human health, $\mathrm{OH}$ picks up on and valorises the broader social factors that influence the transmission of disease. In an editorial on Zika virus in Singapore, Lysaght and colleagues ${ }^{25}$ comment on features of the outbreak and possible solutions that might be missed without an awareness of $\mathrm{OH}$. Thirty-eight of the 56 initial confirmed cases of Zika in Singapore involved transient foreign workers on a construction site in the city. Furnishing these workers with safe and mosquito-free working conditions and housing is one way of combating disease spread suggested by an $\mathrm{OH}$ approach, as is providing foreign workers and their sexual partners with affordable disease testing and options for safe sex.

Since OH draws attention to 'upstream' factors that influence disease transmission, it can help support a case for longer term and broader strategies to prevent the development and spread of EIDs. So in the case of Hendra virus mentioned above, land clearing is a by-product of human population growth and of pursuing certain types of development to service increasing populations. Reconsidering policies around population growth and forms of housing and development could form part of an alternative that arises by focusing on an $\mathrm{OH}$ approach. ${ }^{24} 26$

When ethical frameworks are regarded as a procedural tool then, the $\mathrm{OH}$ perspective can broaden and strengthen considerations to be included in the mix within existing ethical frameworks deployed in bioethics and public health. This aligns with a principle of parsimony that appears to underpin the caution expressed by Verweij and Bovenkerk ${ }^{4}$ regarding any expansionist claims on the part of $\mathrm{OH}$ ethics.

\section{Frameworks as embodying values}

If frameworks are considered to be more substantive than on the view outlined above, such that they embed particular values in how they are structured and/or how they function, then we argue $\mathrm{OH}$ has the resources to generate its own framework, since it is defined by a number of principles that set it apart from existing frameworks. In this respect, $\mathrm{OH}$ differs from bioethics, say, which is simply concerned with ethics as they pertain to a specific area, namely the biological sciences. $\mathrm{OH}$ does not circumscribe an area of concern, but rather describes a specific approach to a particular set of issues.

Three important clarifications need to be made before proceeding. First, we are not seeking to articulate an $\mathrm{OH}$ framework. What we are doing is articulating the kind of principles and values that could comprise and be promoted by such a framework. Second, as it stands, $\mathrm{OH}$ is an approach to disease management grounded in scientific evidence; it is not a normative theory. However, with additional premises, central tenets from $\mathrm{OH}$ can support normative claims, and furthermore, $\mathrm{OH}$ is suggestive of change in the ethical and public health policy status quo. Taking $\mathrm{OH}$ seriously can lead to a rethinking of the legitimate relations between humans and the non-human world. For instance, if we reformulate health as a universal good (as argued for by Degeling and Kerridge ${ }^{27}$ ), then this may illuminate similarities between human and non-human animals that push us to reconsider the different moral treatment routinely accorded humans as opposed to animals. Finally, we are appealing to what may be considered an ideal version of $\mathrm{OH}$, that is, we take seriously the principles espoused by advocates of $\mathrm{OH}$ rather than how these principles might be diluted or compromised in practice.

One of the fundamental principles underpinning $\mathrm{OH}$ is collaboration, and this collaboration is on two fronts. $\mathrm{OH}$ is interdisciplinary: it calls for research and work across disciplines in the sciences, social sciences and humanities. Policy makers, planners, regulators, physicians, veterinarians, ecologists, public and animal health officials and others should work together in spite of their disciplinary differences to pursue $\mathrm{OH}$ objectives. $\mathrm{OH}$ is also concerned to advocate for study and action across human, animal and environmental domains, dissolving the boundaries that have traditionally separated these areas. Thus, OH's approach to collaboration can support a reformist agenda. To be an adherent of $\mathrm{OH}$ is to maintain that breaking down the silos that separate the humanities, and the medical and social sciences related to human disease, animal disease and ecological concerns is the most effective way of managing disease. Such a move challenges the status quo within public health policy that cordons off human health concerns from those of non-human animals.

Another central feature of $\mathrm{OH}$ is its promotion of a configurationist model of infectious disease causation. ${ }^{i}$ As well as the inter-relationships between human systems, and their natural and social contexts, such a model emphasises the ecological, sociopolitical and economic structures that drive infectious disease emergence, transmission and spread. ${ }^{12} 28$ Construing EIDs in this way means that certain remedies will be preferred over others and some will be obscured or ruled out by $\mathrm{OH}$. So although responses guided by contaminationist thinking have been applied in the practice of $\mathrm{OH}$, there is an impetus to promote broad institutional and structural reforms that reconfigure 'upstream' drivers, thereby circumventing the emergence of infectious diseases in the first place. ${ }^{2632}$ For adherents to $\mathrm{OH}$ as a driver for 'upstream' interventions then, it will not be the case that all options can equally be entertained. First and foremost, responses to disease threats that promote configurationist goals must be prioritised.

Furthermore, $\mathrm{OH}$ challenges common public health responses to EID which, as a matter of principle, prioritise humans at the expense of non-humans. Such responses are underpinned by an assumption that this is essential for human well-being and justified by a belief in the superior status of humans. This kind of reasoning is disputed by $\mathrm{OH}$. $\mathrm{OH}$ takes seriously the factual interdependence of human, animal and ecological health such that to achieve health in any one domain requires health in these other domains. Arguably nascent in $\mathrm{OH}$ is an approach to justice that shares equitably the burdens and benefits of EID management across the human, animal and environmental spheres. ${ }^{27} 29$

Beyond having these principles to which $\mathrm{OH}$ could appeal as foundational for a new framework, we want to suggest there are a number of strategic reasons why advocates of $\mathrm{OH}$ might push for such a framework.

If advocates take seriously the health of non-human animals and the environment, then this furnishes a good reason to pursue a specifically $\mathrm{OH}$ framework. The 'public' in public health is always entirely human ${ }^{142730}$ so that rather than try to contort $\mathrm{OH}$ concerns to fit within anthropocentrically conceived frameworks, it may be preferable to situate non-anthropocentric concerns at the centre of a new framework.

${ }^{\mathrm{i}}$ Configurationist models are distinguished from contaminationist and dispositional ones. The latter focus on host and pathogen characteristics and interactions, and invoke 'downstream' responses to disease outbreaks such as eradication and imposition of barriers to limit transmission. 
In a pluralist schema, it seems that $\mathrm{OH}$ alternatives may be disadvantaged not just because they are in competition with other options, but by virtue of the kind of options $\mathrm{OH}$ generates. $\mathrm{OH}$ solutions are demanding, perhaps more so than non-OH ones. $\mathrm{OH}$ calls attention to the need for major structural change and reform in contexts where it is more common to focus narrowly on individualising risk and responsibility. $\mathrm{OH}$ frequently brings into view alternatives that are more distant in space and time such that they may be less obvious in their immediate impact and visibility. ${ }^{31}$ This is in a political environment where the prevailing political imperatives are to institute high visibility strategies that appear to demonstrate definitively to the public that action is being taken. For instance, consider the proposal we suggested above regarding the management of Hendra disease through limiting population growth and resisting development based around clearing key flying fox habitat. Framed in this way, it is easy to see why such a strategy is likely to be politically difficult compared with high visibility and proactive approaches such as the culling of bats, even though such a strategy is likely to worsen the problem. ${ }^{27}$ Whereas if decisions are already being made inside a framework that embodies a commitment to $\mathrm{OH}$, there are no 'cheap and dirty' alternatives on offer to push out $\mathrm{OH}$ options. ${ }^{\text {ii }}$

$\mathrm{OH}$ proposals are also in some senses more novel and less 'tried and tested' in comparison with other strategies, so that even though they are potentially more effective in many cases, they may not be preferred when more familiar and less politically disruptive options are ready to hand. Instituting change is difficult due to a variety of factors including individual and structural inertia, potentially making $\mathrm{OH}$ proposals less appealing and less likely to be adopted.

There are however other prudential reasons that may tell against developing an $\mathrm{OH}$-specific framework. Historically, $\mathrm{OH}$ has been promoted by veterinarians, which may mean an $\mathrm{OH}$ framework would be viewed unfavourably by individuals from disciplines such as medicine and public health. It might also be the case that decision makers in these disciplines would not be prepared to accept $\mathrm{OH}$ in its entirety but may instead be persuaded on particular matters to consider $\mathrm{OH}$ proposals inside a non-OH-specific framework.

\section{CONCLUSION}

Whether $\mathrm{OH}$ requires a new ethical framework depends to some extent on how frameworks are construed. $\mathrm{OH}$ can get by without generating a new framework, instead slotting into existing ethical frameworks if these are held to be value-neutral tools in a procedural approach to decision making. Arguably, however, in doing this, $\mathrm{OH}$ is not living up to its potential. $\mathrm{OH}$ has the resources available to develop a framework that ensures its central concerns are not sidelined, and furthermore, attempting to develop such a framework might be fruitful not only in terms of delivering a new framework for EIDs in public health, but in helping clarify thinking on $\mathrm{OH}$. There is much productive work that can be done by philosophers in teasing out and working up the hitherto underexplored values of $\mathrm{OH}$ and in trying to work out how it might be possible to sort through and prioritise the completing claims of an $\mathrm{OH}$ ethics. Ultimately, however, we remain agnostic on the question of whether

\footnotetext{
${ }^{i i}$ This means of course that a $\mathrm{OH}$ ethical framework has, perhaps, won some prior battle to be selected as the framework to be used, and that other frameworks which might appeal to such alternatives have not been chosen.
}

$\mathrm{OH}$ requires a novel ethical framework. We have laid out the terrain showing that $\mathrm{OH}$ has the theoretical resources to both contribute to existing pluralistic frameworks and to support the development of its own (in collaboration with relevant experts), but whether its advocates choose to pursue this is perhaps best left up to them. After all, practitioners rather than philosophers may be better placed to understand the political and strategic climate in which public health decision making operates.

Acknowledgements A version of this paper was presented at the 2017 Society for Applied Philosophy Conference in Copenhagen, and we would like to thank attendees for their very helpful feedback.

Contributors $\mathrm{J}$ and CD conceived the idea for the paper. JJ produced a draft that CD reviewed, and $J$ Incorporated suggestions in an updated draft. JJ and CD revised the paper in light of reviewer comments, and both authors approve of the final manuscript.

Funding Research for this paper was supported by funding from the Australian National Health and Medical Research Council, Grant number APP1083079.

Competing interests None declared.

Patient consent for publication Not required.

Ethics approval Ethics approval was not required for this research.

Provenance and peer review Not commissioned; externally peer reviewed.

\section{REFERENCES}

1 Lim SS, Vos T, Flaxman AD, et al. A comparative risk assessment of burden of disease and injury attributable to 67 risk factors and risk factor clusters in 21 regions, 1990 2010: a systematic analysis for the Global Burden of Disease Study 2010. Lancet 2012;380:2224-60.

2 Berthe FCJ, Bouley T, Karesh WB, et al. Operational framework for strengthening human, animal and environmental public health systems at their interface. Washington, D.C: The World Bank for International Development, 2018.

3 Kakkar M, Abbas SS. One health: moving from concept to reality. Lancet Infect Dis 2011;11:808.

4 Verweij M, Bovenkerk B. Ethical Promises and Pitfalls of OneHealth. Public Health Ethics 2016:9:1-4.

5 Grace D, Jones B. Zoonoses (Project 1): Wildlife/domestic livestock interactions. Final project report to DFID submitted by the International Livestock Research Institute (ILRI) and Roya/ Veterinary College. London: IRLI, 2011.

6 Marabelli R. The role of official veterinary services in dealing with new social challenges: animal health and protection, food safety, and the environment. Rev SC Tech 2003;22:363-71.

7 Rock MJ, Degeling C. Public health ethics and more-than-human solidarity. Soc Sci Med 2015;129:61-7.

8 Degeling C, Lederman Z, Rock M. Culling and the common good: re-evaluating harms and benefits under the one health paradigm. Public Health Ethics 2016;9:244-54.

9 Zinsstag J, Schelling E, Waltner-Toews D, et al. From "one medicine" to "one health" and systemic approaches to health and well-being. Prev Vet Med 2011;101:148-56.

10 Lee K, Brumme ZL. Operationalizing the One Health approach: the global governance challenges. Health Policy Plan 2013;28:778-85.

11 Lapinski MK, Funk JA, Moccia LT. Recommendations for the role of social science research in one health. Soc Sci Med 2015;129:51-60.

12 Hinchliffe $S$. More than one world, more than one health: re-configuring interspecies health. Soc Sci Med 2015;129:28-35.

13 Mazet JA, Uhart MM, Keyyu JD. Stakeholders in one health. Rev Sci Tech 2014:33:443-52

14 Capps B, Bailey MM, Bickford D, et al. Introducing one health to the ethical debate about zoonotic diseases in southeast Asia. Bioethics 2015;29:588-96.

15 Degeling C, Johnson J, Ward M, et al. A delphi survey and analysis of expert perspectives on one health in Australia. Ecohealth 2017;14:783-92.

16 Capps B, Lederman Z. One health, vaccines and ebola: the opportunities for shared benefits. Journal of Agricultural and Environmental Ethics 2015;28:1011-32.

17 Zinsstag J, Mackenzie JS, Jeggo M, et al. Mainstreaming one health. Ecohealth 2012:9:107-10.

18 Dawson A. Theory and practice in public health ethics: a complex relationship. Public Health Ethics and Practice 2009:191-210.

19 Grill K, Dawson A. Ethical frameworks in public health decision-making: defending a value-based and pluralist approach. Health Care Anal 2017;25:291-307.

20 Lee LM. A bridge back to the future: public health ethics, bioethics, and environmental ethics. Am J Bioeth 2017:17:5-12.

21 Field $\mathrm{H}$, Crameri G, Kung NY, et al. Ecological aspects of hendra virus. Curr Top Microbiol Immunol 2012;359:11-23.

22 Plowright RK, Eby P, Hudson PJ, et al. Ecological dynamics of emerging bat virus spillover. Proc Biol Sci 2015;282:20142124. 
23 Breed $\mathrm{AC}$, Field $\mathrm{HE}$, Epstein $\mathrm{JH}$, et al. Emerging henipaviruses and flying foxes Conservation and management perspectives. Biol Conserv 2006;131:211-20.

24 Patz JA, Daszak P, Tabor GM, et al. Unhealthy landscapes: Policy recommendations on land use change and infectious disease emergence. Environ Health Perspect 2004;112:1092-8.

25 Lysaght T, Lee TL, Watson S, et al. Zika in Singapore: insights from One Health and social medicine. Singapore Med J 2016:57:528-9.

26 McFarlane RA, Sleigh AC, McMichael AJ. Land-use change and emerging infectious disease on an island continent. Int I Environ Res Public Health 2013;10:2699-719.

27 Degeling C, Kerridge I. Hendra in the news: public policy meets public morality in times of zoonotic uncertainty. Soc Sci Med 2013;82:156-63.
28 Wallace RG, Bergmann L, Kock R, et al. The dawn of structural one health: a new science tracking disease emergence along circuits of capital. Soc Sci Med 2015;129:68-77.

29 Lysaght T, Capps B, Bailey M, et al. Justice is the missing link in one health: results of a mixed methods study in an urban city state. PLoS One 2017;12:e0170967.

30 Blue G, Rock M. Trans-biopolitics: Complexity in interspecies relations. Health 2011;15:353-68

31 Buse CG, Smith M, Silva DS. Attending to scalar ethical issues in emerging approaches to environmental health research and practice. Monash Bioeth Rev 2018.

32 Whitmee S, Haines A, Beyrer C, et al. Safeguarding human health in the anthropocene epoch: report of the rockefeller foundation-lancet commission on planetary health. The Lancet 2015:386:1973-2028. 